\title{
Comparison of Phosphoric Acid 37\% and Er:YAG Laser Used to Prepare Dental Enamel Palatal Surface before Bonding Braces
}

Pinheiro LL, Pinheiro NL, Cavalcanti MF*, Cordeiro JM, Marcos RL, dos Santos MT and Frigo L

Laboratory of Biophotonics, Nove de Julho University, Av. Paranaguá- Vila Paranagua, São Paulo, Brazil

\begin{abstract}
Background: Adhesion of braces to dental enamel is critical for orthodontic treatments, for that purpose, phosphoric acid has been used successfully to prepare dental enamel surface before bonding braces. ER:YAG laser has proved ability to do the same over buccal surfaces of dental enamel, but the increasing interest for lingual orthodontics leaded to the question whether ER:YAG laser can prepare equally palatal and buccal surfaces for bonding lingual braces.

Material and methods: 15 teeth that were extracted for clinical purposes were microscopic electronic scanned (MES) before treatment, after phosphoric acid 37\%, and after ER:YAG laser irradiated, images of buccal and palatal faces after each treatment were analyzed by image $\mathrm{J}$ software.

Results: After all treatments enamel surfaces were mostly type 1 , no statistically significant differences were found between groups.

Conclusion: phosphoric acid $37 \%$ and the used dose of Er:YAG laser can successfully prepare dental enamel surface before bonding braces over buccal and palatal faces of teeth.
\end{abstract}

Keywords: Orthodontics; Orthodontic braces; Braces bondingmethods; Lasers, Dental enamel - Irradiation effects; Biophotonics

\section{Introduction}

Adhesion of composite to teeth increased significantly in the last decades, mostly of that is because of enamel conditioning [1] that increased bond strength and raised dentistry to a higher level of quality, moreover, increasing of bonding forces (5,8 $\mathrm{MPa}$ to 7,8 $\mathrm{MPa}$ ) [2] also changed orthodontic treatments.

Many orthodontic therapies have been developed since Angle proposed Orthodontics as the first dental specialty, the majority of them bonds braces to the buccal faces of teeth, but for aesthetic purposes, braces have been bonded to lingual faces also, that raised the question whether it is possible to produce similar conditioning of buccal and palatal enamel surfaces.

The bond strength increasing is due partially to the action of phosphoric acid $37 \%$ that decalcifies enamel surface, exposing tags and creating mechanic retention to composite [3], but bond strength is also influenced by physical and mechanical properties of bonding materials, by mouth humidity, and design of the bracket base [4] Silverstone et al. (1987) [5], using microscopic electronic scanning (MES), described three different patterns for conditioned enamel, 1-the most frequent, decalcification in the center of the enamel prisms, 2-decalcification in the neighborhood of the prisms, and 3-combination of both of them.

Erbium: yttrium aluminum garnet (Er:YAG) laser has been used for surgical purposes to cut soft and hard tissues in medicine and dentistry [6].

During irradiation, Er:YAG laser energy is absorbed by water molecules, evaporating organic components in a photo thermal reaction that increases pressure inside hard tissues, causing micro explosions [3], enamel conditioning using laser also exposes tags, inducing thermal changes to enamel surface like fusion and tags crystallization [3], changing enamel morphology that create craters and cracks [7].
In dentistry Er:YAG laser has been used to cut dental hard tissues, dentin and enamel, removing cavities and, just like phosphoric acid $37 \%$, to prepare dental surfaces before bonding composite to increase bonding forces [8].

In orthodontics it has been used to prepare enamel surface before bonding braces to buccal faces of teeth.

\section{Objective}

This work presents Er:YAG laser as an alternative to the mostly used phosphoric acid $37 \%$ to prepare palatal dental enamel surfaces before bonding braces, for that we compared SEM of buccal and palatal faces of teeth conditioned by phosphoric acid $37 \%$ and Er:YAG laser.

\section{Material and Methods}

This work was approved by the Ethics committee of Cruzeiro do Sul University, protocol number 040-2015, and respected all ethical concerns related to studies using organs donated by living people.

\section{Methods}

Sample collection: Teeth were collected by the surgeon, cleaned using a rubber cup and pumice (SS White São Paulo, Brazil), and stored in a box covered by PBS $0.9 \%$ until use.

*Corresponding author: Cavalcanti MF, Laboratory of Biophotonics, Nove de Julho University, Av. Paranaguá, 2070 - Vila Paranagua, São Paulo, Brazil, Tel: +55 11 2541-5779; E-mail: mxistocavalcanti@gmail.com

Received January 29, 2018; Accepted March 12, 2018; Published March 19 2018

Citation: Pinheiro LL, Pinheiro NL, Cavalcanti MF, Cordeiro JM, Marcos RL, et al (2018) Comparison of Phosphoric Acid 37\% and Er:YAG Laser Used to Prepare Dental Enamel Palatal Surface before Bonding Braces. J Laser Opt Photonics 5 : 178. doi: 10.4172/2469-410X.1000178

Copyright: (c) 2018 Pinheiro LL, et al. This is an open-access article distributed under the terms of the Creative Commons Attribution License, which permits unrestricted use, distribution, and reproduction in any medium, provided the original author and source are credited. 
Immediately before use, teeth were numbered from 1 to 15 and at palatal and buccal faces were drawn squares on the left and on the right sides of the crowns (Figure 1 and Table 1).

\section{Scanning electron microscopy (SEM) assay}

Scanning device: Microscope FEI, model Quanta 600, software Inca-Wave Oxford. Images were obtained and analyzed at MAHLE Metal Leve S.A., RDMLM-Metallurgy and Mechanical Properties Laboratory, Jundiaí, Brazil.

Untreated control protocol: Before treatment, teeth were fixed upon a holder and buccal and palatal faces were scanned at $75 \mathrm{x}, 500 \mathrm{x}$, $1.000 x$ e $1.500 x$ (Figure 2).

Enamel etching protocol: After first scanning, teeth (left squares) were conditioned using Phosphoric acid 37\%, for 45 seconds and scanned $[9,10]$.

Laser device: High level Er:YAG laser, laser Kavo, Model Kavokey, Joinville, Brazil, infrared wavelenght $2.94 \mu \mathrm{m}$, pulse 60 to $500 \mathrm{~mJ}$, frequency 1 to $15 \mathrm{~Hz}$, pulse duration 250 to $500 \mathrm{~ms}$ spot area $0.63 \mathrm{~mm}^{2}$.

Irradiation protocol: After phosphoric acid conditioning, teeth (right squares) were Er:YAG laser irradiated with $80 \mathrm{~mJ}$ pulse, $4 \mathrm{~Hz}$ frequency, for 250-500 $\mu$ s pulse time exposure, $250 \mathrm{~ms}$ pulse pause, 12 $\mathrm{mm}$ distant from irradiated surface, and water refrigerated [11] (Table 2).
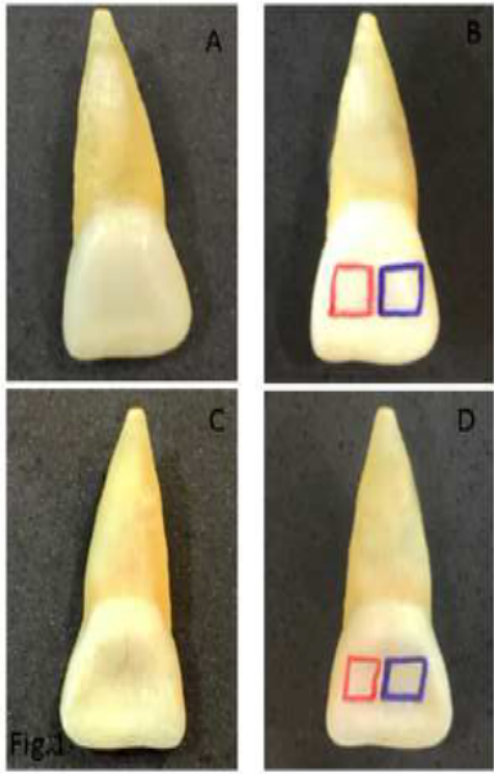

Figure 1: A-buccal face of the tooth, B-squares drawn at the buccal face of dental crown, right square will receive Er:YAG laser, left square will receive phosphoric acid 37\%, C-palatal face of the tooth, D-squares drawn at the palatal face of dental crown, right square will receive Er:YAG laser, left square will receive phosphoric acid $37 \%$.

\begin{tabular}{|l|c|c|c|}
\hline Group & Face & Treatment & N \\
\hline $\begin{array}{l}\text { Group 1 } \\
\text { (Left side of tooth) }\end{array}$ & A (Vestibular) & Phosphoric acid 37\% & 15 \\
\hline $\begin{array}{l}\text { Group 2 } \\
\text { (Left side of tooth) }\end{array}$ & B (Palatal) & Phosphoric acid 37\% & 15 \\
\hline $\begin{array}{l}\text { Group 3 } \\
\text { (Right side of tooth) }\end{array}$ & A (Vestibular) & Laser de Er:YAG & 15 \\
\hline $\begin{array}{l}\text { Group 4 } \\
\text { (Right side of tooth) }\end{array}$ & B (Palatal) & Laser de Er:YAG & 15 \\
\hline
\end{tabular}

Table 1: Study design.

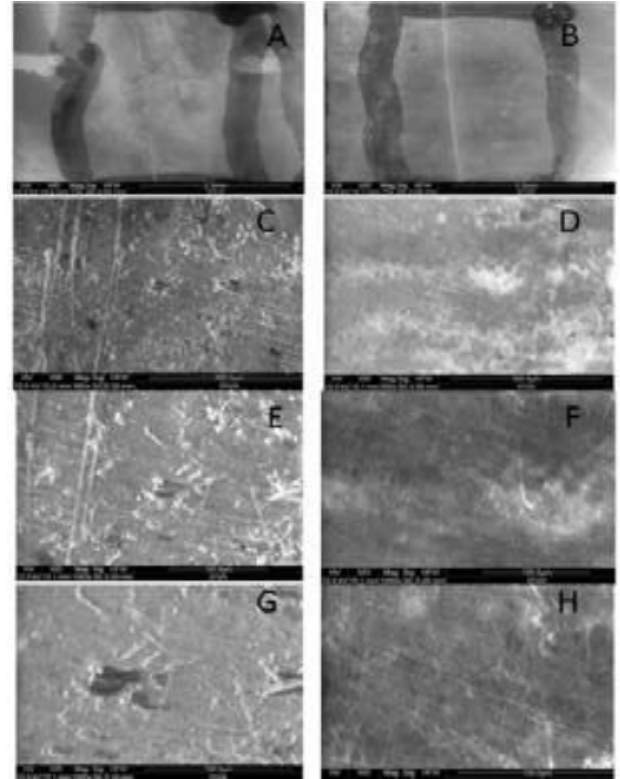

Figure 2: A-square drawn at buccal face of the tooth before treatment 75x, Bsquare drawn at palatal face of the tooth before treatment $75 x, \mathrm{C}$-buccal face of the tooth before treatment $500 x$, D-palatal face of the tooth before treatment $500 x$, E-buccal face of the tooth before treatment 1000x, F-palatal face of the tooth before treatment $1000 x$, G-buccal face of the tooth before treatment $1500 x, \mathrm{H}$-palatal face of the tooth before treatment 1500x.

\begin{tabular}{|c|c|c|c|c|c|c|}
\hline Wavelength & $\begin{array}{c}\text { Power } \\
\text { density or } \\
\text { irradiance }\end{array}$ & $\begin{array}{c}\text { Pulse } \\
\text { energy }\end{array}$ & $\begin{array}{c}\text { Pulse } \\
\text { frequency }\end{array}$ & $\begin{array}{c}\text { Pulse } \\
\text { time } \\
\text { exposure }\end{array}$ & $\begin{array}{c}\text { Pulse } \\
\text { pause }\end{array}$ & $\begin{array}{c}\text { Energy } \\
\text { density } \\
\text { or dose }\end{array}$ \\
\hline $2.94 \mu \mathrm{m}$ & $\begin{array}{c}3650 \mathrm{~W} / \\
\mathrm{mm}^{2}\end{array}$ & $80 \mathrm{~mJ}$ & $4 \mathrm{HZ}$ & $\begin{array}{c}250-500 \\
\mu \mathrm{s}\end{array}$ & $250 \mathrm{~ms}$ & $23 \mathrm{KJ}$ \\
\hline
\end{tabular}

Table 2: Irradiation parameters.

Image analysis: Images of all treated groups were analyzed using image J program.

Statistical analysis: Test t Student $\mathrm{p}<0.05 \%$ was used to compare:

1. Buccal and palatal images after enamel etching,

2. Buccal and palatal images after laser irradiation,

3. Buccal images after enamel etching and after laser irradiation,

4. Palatal images after enamel etching and after laser irradiation.

\section{Results}

All treatments produced a very similar conditioning of the enamel surface after Image J software analyze. (Figures 3-5) There were no statistically significant differences neither while variant was the treatment (phosphoric acid 37\% and Er:YAG laser) nor while the variant was the tooth face (buccal and palatal) for the same treatment, (Table 3 and Figure 6A) moreover, compared to untreated control all of them were statistically significant (Figure 6B).

The majority of the buccal faces presented enamel surface pattern [5] type 1 after treatment, phosphoric acid 37\% did not present any type 2 but presented $26.6 \%$ of type 3 and Er:YAG laser presented $6.6 \%$ of type 2 but did not present any type 3 (Figure 6C and 6D).

Over palatal faces, the majority of treatments also presented surface pattern type 1 , but phosphoric acid $37 \%$ presented $20 \%$ of type 2 and 
Citation: Pinheiro LL, Pinheiro NL, Cavalcanti MF, Cordeiro JM, Marcos RL, et al. (2018) Comparison of Phosphoric Acid 37\% and Er:YAG Laser Used to Prepare Dental Enamel Palatal Surface before Bonding Braces. J Laser Opt Photonics 5: 178. doi: 10.4172/2469-410X.1000178

Page 3 of 5
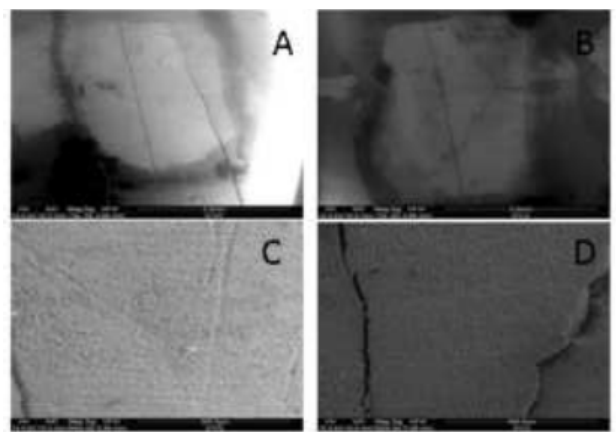

C
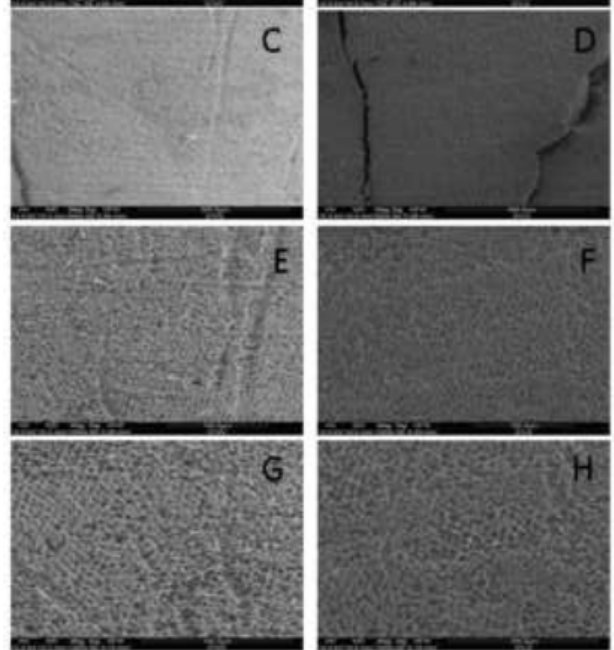

Figure 3: Comparison of buccal and palatal faces of teeth treated using phosphoric acid $37 \%$. A-left square drawn at buccal face of the tooth that received phosphoric acid $37 \%, 75 \mathrm{X}$, B-left square drawn at palatal face of the tooth that received phosphoric acid 37\%, 75X, C-left square, buccal face, after treatment, 500X, D-left square, palatal face, after treatment, 500X, E-left square, buccal face, after treatment, 1000X, F-left square, palatal face, after treatment, 1000X, G-left square, buccal face, after treatment, 1500X, H-left square, palatal face, after treatment, 1500X.
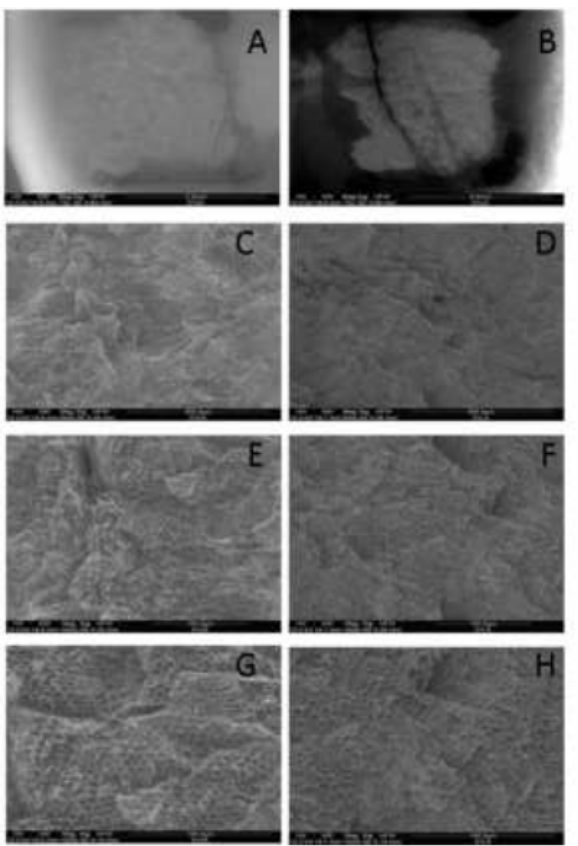

Figure 4: Comparison of buccal and palatal faces of teeth treated using Er:YAG laser. A-right square drawn at buccal face of the tooth that received Er:YAG laser, 75X, B-right square drawn at palatal face of the tooth that received $\mathrm{Er}$ : YAG laser, 75X, C-right square, buccal face, after treatment, 500X, D-right square, palatal face, after treatment, 500X, E-right square, buccal face, after treatment, 1000X, F-right square, palatal face, after treatment, 1000X, G-right square, buccal face, after treatment, 1500X, H-right square, palatal face, after treatment, 1500X
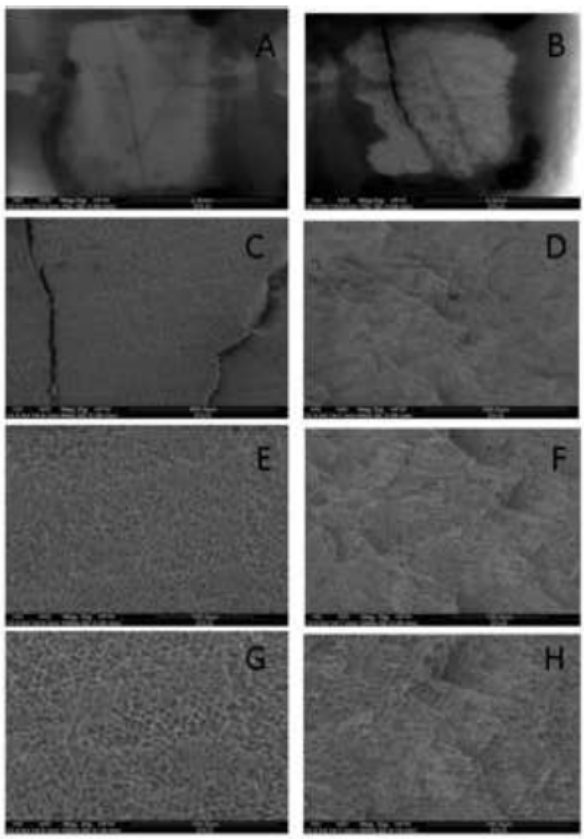

Figure 5: Comparison of palatal faces of teeth treated using phosphoric acid $37 \%$ and Er:YAG laser. A-left square drawn at palatal face of the tooth that received phosphoric acid 37\%, 75X, B-right square drawn at palatal face of the tooth that received Er:YAG laser, 75X, C-left square, palatal face, after phosphoric acid 37\%, 500X, D-right square, palatal face, after Er:YAG laser $500 X$, E-right square, buccal face, after phosphoric acid 37\%, 1000X, F-right square, palatal face, after Er:YAG laser, 1000X, G-right square, buccal face, after phosphoric acid $37 \%, 1500 \mathrm{X}, \mathrm{H}$-right square, palatal face, after Er:YAG laser, 1500X.

\begin{tabular}{|c|c|c|c|}
\hline Comparison of Treatments & $\mathbf{n = 1 5}$ & $\mathbf{n = 1 5}$ & $\mathbf{P}$ \\
\hline Vestibular etching $\times$ Vestibular Laser & $196.99 \pm 37.71$ & $186.45 \pm 43.39$ & 0.246 \\
\hline Palatal etching $\times$ Palatal Laser & $200.98 \pm 38.47$ & $202.19 \pm 38.84$ & 0.466 \\
\hline Vestibular etching $\times$ Palatal etching & $196.99 \pm 37.71$ & $200.98 \pm 38.47$ & 0.390 \\
\hline Vestibular Laser $\times$ Palatal Laser & $186.45 \pm 43.39$ & $202.19 \pm 38.84$ & 0.152 \\
\hline
\end{tabular}

$\mathrm{n}$ : sample size; $\mathrm{p}$ : significance; Test t Student;

Table 3: Comparison of treatments (phosphoric acid 37\% and Er:YAG laser).

$13 \%$ of type 3 and Er:YAG laser presented $6.6 \%$ of type 2 and $6.6 \%$ of type 3 (Figure 6E and 6F).

\section{Discussion}

Nowadays mostly of the orthodontic braces are bonded to the enamel surface, so that to orthodontic treatment success, this adhesion should remain strong until the treatment has finished, resisting to occlusal and to orthodontic forces, without causing damage to the tooth during braces removal.

Enamel etching was initially described by Buonocore [1], this procedure increased adhesion of braces to enamel and improved significantly orthodontic practice.

Phosphoric acid $37 \%$ applied to the buccal surface of enamel can produce micro retentions, promoting a well prepared surface for bonding braces, so that it is considered the "state of the art" material used for this purpose $[5,12,13]$, but as duration of enamel exposition to phosphoric acid $37 \%$ can produce different results, enamel surface morphology was studied after exposition for 15 to 60 seconds, leading to the clinically accepted etching protocol of 45 seconds $[9,10]$.

Despite DE JESUS TAVAREZ, 2017 [14] stated that bond strength 


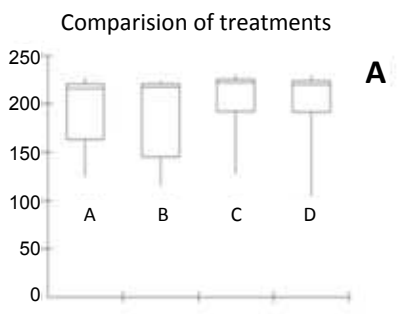

A

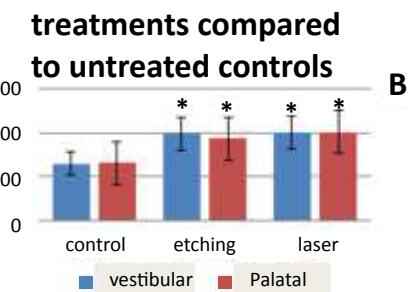

phosphoric acid 37\% (vestibular face)

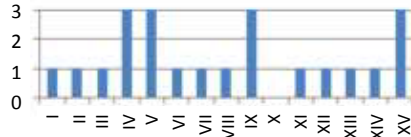

phosphoric acid 37\% (palatal face) D

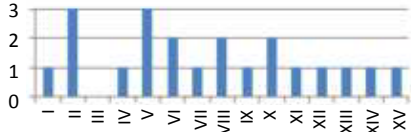

Er:YAG laser (vestibular face)

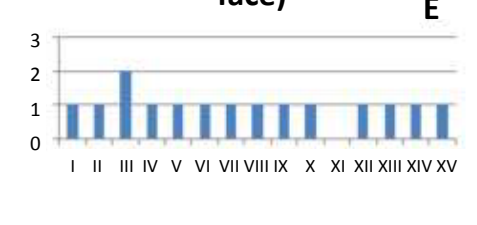

(palatal face) Er:YAG

laser

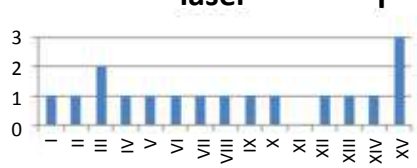

Figure 6: (A) Results shows no statistically significant differences among all treated groups. ( $p>0.05)$; (B) Compared to untreated control all groups presented results statistically significant. ( $p>0.05$ ); (C) Buccal face after phosphoric acid $37 \%$, type 1 pattern predominant, axis $X$ tooth number, axis $Y$ surface pattern; (D) Buccal face after Er:YAG laser, type 1 pattern predominant, axis $X$ tooth number, axis $Y$ surface pattern; (E) Palatal face after phosphoric acid $37 \%$, type 1 pattern predominant, axis $X$ tooth number, axis $Y$ surface pattern; (F) Palatal face after Er:YAG laser, type 1 pattern predominant, axis $X$ tooth number, axis $Y$ surface pattern.

is higher after phosphoric acid 37\%, Er:YAG laser can promote enough ablation without enamel fractures [15], without signs of thermal injuries [16-18] producing enamel conditioning over buccal faces of teeth similar to phosphoric acid $37 \%[8,19-21]$.

Our work answers the question raised by lingual orthodontic therapies whether phosphoric acid $37 \%$ and Er:YAG laser could produce similar results conditioning buccal and palatal faces of dental enamel.

The majority of the buccal and palatal faces presented surface type 1 after treatment, despite our results showed micro cracks, they were already present before treatment, in the control group, what infers that this dose of Er:YAG laser did not increase the amount of cracks, moreover, no statistically significant differences were present among all treated groups, but laser irradiated teeth presented different levels of irregularities over the surface, increasing the contact surface and the mechanical bonding that can lead to increasing bond strength.

\section{Conclusion}

Comparing dental enamel surface microscopy scanning's (SEM) after phosphoric acid $37 \%$ etching for 45 seconds and after irradiation the dose of infrared $(2.94 \mu \mathrm{m})$ laser ER:YAG, $12 \mathrm{~mm}$ distant from irradiated surface, water refrigerated, it is possible to affirm that both treatments can produce similar patterns of micro retentions, moreover, phosphoric acid 37\% and Er:YAG laser can successfully prepare dental enamel surface before bonding braces over buccal and palatal faces of teeth.

\section{References}

1. Buonocore MG (1955) A Simple Method of Increasing the Adhesion of Acrylic Filling Materials to Enamel Surfaces. J Dent Res 34: 849-853.

2. Reynolds IR (1975) A Review of Direct Orthodontic Bonding. Br J Orthod 2: 171-178.

3. Souza-Gabriel AE, Chinelatti MA, Borsatto MC, Pécora JD, Palma-Dibb RG, et al. (2008) SEM Analysis of Enamel Surface Treated by Er:YAG Laser: Influence of Irradiation Distance. Microsc Res Tech 1: 536-541.

4. Menezes-Silva R, dos Reis LA, Tostes BO, de Oliveira WD, Santos MH, et al. (2015) Bond strength of brackets bonded with chemically and light activated materials after thermal cycling. Advances in Materials Physics and Chemistry 5: 351 .
5. Silverstone LM, Saxton CA, Dogon IL, Fejerskov O (1975) Variation in the Pattern of Acid Etching of Human Dental Enamel Examinated by Eletron Microscopy. Caries Res 9: 373-387.

6. Kale LN, Garde JB, Garde SS, Gupta P (2017) Evolution and applications of lasers in oral and maxilla facial surgery. Journal of Dental and Allied Sciences 6: 28 .

7. Marraccini TM, Bachmann L, Wigdor HA, Walsh JTJR, Stabholtz A, et al (2005) Morphological Evaluation of Enamel and Dentin Irradiated with 9,6 mm CO2 and 2,94mm Er:YAG lasers. Lasers Phys Lett 2 551-555.

8. Basaran G, Hamamci, N, Akkurt A (2011) Shear Bond Strength of Bonding to Enamel with Different Laser Irradiation Distances. Lasers Med Sci 26: 149-56.

9. Barkmeier WW, Erickson RL, Kimmes NS, Latta MA, Wilwerding TM (2009) Effect of Enamel Etching Time on Roughness and Bond Strength. Operative Dentistry 34: 217-222.

10. Barkmeier WW, Shaffer SE, Gwinnett AJ (1986) Effects of 15 vs 60 second enamel acid conditioning on adhesion and morphology. Oper Dent 11: 111-116.

11. Bispo LB, Matson E, Mondelli J (2005) Adhesive strength of dental enamel after conditioning with Er: YAG laser / Bond strength of the dental enamel after conditioning with the Er: YAG laser. JBD, Rev. Íbero-Am. Odontol. Estét. Dent. Oper 4: 140-151.

12. Sharpe AN (1967) Influence of the Cristal Orientation in Human Enamel on its Reactivity to Acid as Shown by High Resolution Microradiography. Arch Oral Biol 12: 583-591.

13. Silverstone LM, Saxton CA, Dogon IL, Fejerskov O (1987) Variation in the Pattern of Acid Etching of Human Dental Enamel Examined by Scanning Electron Microscopy. Caries Res 9: 373-387.

14. De Jesus Tavarez RR, Bezerra GL, de Souza Penha KJ, Gomes Torres CR, Firoozmand LM (2017) Er:YAG pre-treatment for bonding of orthodontic bracket: 1 year of in vitro treatment. Clin Cosmet Investig Dent 9: 19.

15. Kayano T, Ochiai S, Kiyono K, Yamamoto H, Nakajima S, et al. (1991) Effect of Er:YAG laser irradiation on human extracted teeth. Journal of Clinical Laser Medicine and Surgery 9: 147-150.

16. Keller U, Hibst R (1994) Clinical Applications of the Er:YAG Lasers in Cariology and Oral Surgery. International Conference on Advanced Laser Dentistry 1984: 85-94.

17. Keller U, Hibst R (1993) Effects of Er:YAG Laser on Enamel Bonding of Composite Materials. SPIE Dent Applic Lasers 1880: 163-168.

18. Keller U, Hibst R (1993) Lasers in dentistry. Clinical Application Today and Tomorrow. SPIE Dent Applic Lasers 2080: 2-9. 
Citation: Pinheiro LL, Pinheiro NL, Cavalcanti MF, Cordeiro JM, Marcos RL, et al. (2018) Comparison of Phosphoric Acid 37\% and Er:YAG Laser Used to Prepare Dental Enamel Palatal Surface before Bonding Braces. J Laser Opt Photonics 5: 178. doi: 10.4172/2469-410X.1000178

Page 5 of 5

19. Lee BS, Hsieh TT, Lee YI, Lan Wh, Hsu YJ, et al. (2003) Bond Strengths of Orthodontic Bracket After Acid-Etched, Er:YAG Laser-Irradiated and Combined Treatment on Enamel Surface. Angle Orthod 73: 565-570.

20. Ozer T, Başaran G, Berk N (2008) Laser Etching of Enamel for Orthodontic
Bonding. Am J Orthod Dentofacial Orthop 134: 193-197.

21. Jamenis SC, Kalia A, Sharif k (2011) Comparative Evaluation of Shear Bond Strength of Orthodontic Bracket Using Laser Etching and Two Conventional Etching Techniques: An In Vitro Study. J Indian Orthod Soc 45: 134-139. 